\title{
Effects of Neonatal High-Dose Short-Term Glucocorticoid Treatment on the Lung: A Morphologic and Morphometric Study in the Rat
}

\author{
STEFAN A. TSCHANZ, ANDREW N. MAKANYA, BEAT HAENNI, AND PETER H. BURRI \\ Institute of Anatomy, University of Berne, CH-3000 Berne 9, Switzerland [S.A.T., A.N.M., B.H., P.H.B.], \\ and Department of Veterinary Anatomy, University of Nairobi, Nairobi, Kenya [A.N.M.]
}

\begin{abstract}
ABST
Glucocorticoids are often applied in neonatology and perina-
tology to fight the problems of respiratory distress and chronic
lung disease. There are, however, many controversies regarding
the adverse side effects and long-term clinical benefits of this
therapeutic approach. In rats, glucocorticoids are known to seri-
ously impair the formation of alveoli when applied during the
first two postnatal weeks even at very low dosage. The current
study investigates short-term and long-term glucocorticoid ef-
fects on the rat lung by means of morphologic and morphometric
observations at light and electron microscopic levels. Application
of a high-dosage protocol for only few days resulted in a marked
acceleration of lung development with a precocious microvascu-
lar maturation resulting in single capillary network septa in the
first 4 postnatal days. By postnatal d 10, the lung morphologic
phenotype showed a step back in the maturational state, with an
increased number of septa with double capillary layer, followed
\end{abstract}
by an exceptional second round of the alveolarization process. As a result of this process, there was an almost complete recovery in the parenchymal lung structure by postnatal d 36 , and by $\mathrm{d} 60$, there were virtually no qualitative or quantitative differences between experimental and control rats. These findings indicate that both dosage and duration of glucocorticoid therapy in the early postnatal period are very critical with respect to lung development and maturation and that a careful therapeutic strategy can minimize late sequelae of treatment. (Pediatr Res 53: 72-80, 2003)
GC, glucocorticoid
LM, light microscope
TEM, transmission electron microscope

Abbreviations
GC therapy is widely used in the prenatal and postnatal periods either as a prophylactic or curative measure. Use of prenatal GCs is often motivated by the observed positive effects on lung maturation and surfactant production in preterm babies $(1,2)$, who otherwise stand a high chance of developing respiratory distress syndrome (3) and subsequent chronic lung disease, also known as bronchopulmonary dysplasia $(4,5)$. The positive effects of postnatal GCs on pulmonary inflammatory processes $(6,7)$ and the prophylactic effects against hyperoxic lung injury (8) seem to improve the survival chances of preterm neonates. In perinatal medicine, a variety of therapeutic schemes have been adopted, but controversies regarding the long-term benefits and the negative side effects of GC in neonatology abound $(9-11)$. Indeed, besides the apparent benefits of GC therapy, adverse effects on lung maturation have

Received December 11, 2001; accepted June 3, 2002.

Correspondence: Stefan A. Tschanz, M.D., Institute of Anatomy, University of Berne, Buehlstrasse 26, 3000 Berne 9, Switzerland; e-mail: tschanz@ana.unibe.ch

Supported by grant nos. 31-45831.95 and 31-55895.98 from the Swiss National Science Foundation.

DOI: 10.1203/01.PDR.0000041513.93422.C8 been reported in animal experiments $(12,13)$. Furthermore, reserves have been expressed over the general outcome of treated newborns $(14,15)$. In the recent past, there have been numerous studies on the positive and negative effects of postnatal GC therapy, but as noted by Barrington (16), there are no published long-term pulmonary data.

Previously we have indicated that long-term administration of minute doses of GC results in a permanent impairment of lung alveolarization in postnatal rats $(17,18)$. Alveolarization is achieved by subdivision of the preexisting saccular air spaces by new septa, resulting in an increase in parenchymal complexity (19). We proposed that the impairment of alveolarization by $\mathrm{GC}$ was the result of a precocious induction of microvascular maturation. Indeed, at the time when alveolarization was due to occur, a majority of septa had already undergone microvascular maturation, and, it is generally accepted, mature septa cannot produce new interalveolar walls (17). In that study, duration of dexamethasone treatment was rather long when compared with the situation in newborn infants (d 2-15 in rats corresponds to a time span of several months in humans), but the dosage was 50 to 100 times smaller 
per kilogram of body weight than the one used in human neonatology. In the present study we therefore designed a GC treatment protocol more closely adapted to the human situation regarding dosage and duration, taking also into account the higher susceptibility of rats to GC. We administered a relatively high dose of GC for a rather short period just after birth, i.e. during the saccular stage of lung development.

\section{METHODS}

Animal care. A total of 50 newborn rats from timed pregnant female rats of the Zurich Sprague-Dawley strain were used for the experiments. The mean birth weight of all animals was $6.8 \mathrm{~g} \mathrm{(SD,} 0.5 \mathrm{~g})$. Soon after birth, all litters were reduced to eight male pups per dam. From each of these litters, five individuals were selected to form either a control group or an experimental group, with a total of five groups for each category as detailed below. Animals were maintained in standard cages at an ambient temperature of $21^{\circ} \mathrm{C}$ and raised on standard rat pellets (dams and offspring). Water was allowed ad libitum. The animal experiments were performed in accordance with the Swiss Federal Act on Animal Protection and the Swiss Animal Protection Ordinance.

Drug administration. Experimental animals received a decreasing dose of a Decadron solution (Merck, Sharp \& Dohme, Zurich, Switzerland) for 4 consecutive days ( $1 \mathrm{~mL}$ of Decadron contained $4 \mathrm{mg}$ of dexamethasone phosphate). An appropriate quantity of dexamethasone diluted in isotonic saline was injected s.c. between $0900 \mathrm{~h}$ and $1000 \mathrm{~h}$ from the first (approximately $24 \mathrm{~h}$ postpartum) to the fourth day after birth. On postnatal $\mathrm{d} 1,2,3$, and 4 , the experimental animals received respective dosages of $0.1,0.05,0.025$, and $0.01 \mu \mathrm{g}$ of dexamethasone phosphate per gram of body weight. After dilution, the volumes injected ranged from 20 to $50 \mu \mathrm{L}$. The control animals received equivalent volumes of isotonic saline at time points corresponding to those of the experimental animals.

Lung fixation and tissue processing. On postnatal d 4, 10, 21,36 , and 60 , animals were anesthetized by i.p. administration of a mixture of $0.06 \mathrm{mg}$ of Sedalin (acepromazine), $0.6 \mathrm{mg}$ of Xylapan (xylazine), and $6 \mathrm{mg}$ of Narketan (ketamine; all from Chassot, Switzerland), all per $100 \mathrm{~g}$ body weight. Lungs were fixed according to standard techniques (20), i.e. by intratracheal instillation of a $2.5 \%$ phosphate-buffered glutaraldehyde solution ( $\mathrm{pH} 7.4$, osmolality $360 \mathrm{mOsm}$, pressure head 20 $\mathrm{cm} \mathrm{H}_{2} \mathrm{O}$ ) after inducing a pneumothorax by puncturing the diaphragm. Subsequently, the lungs were dissected free and immersed in toto in the same fixative for at least $24 \mathrm{~h}$ at a temperature of $4^{\circ} \mathrm{C}$. The volumes of individual lung lobes were measured by water displacement (21), the total lung volume being the sum of all lobar volumes.

The right middle lobe was embedded in toto in paraffin for LM investigation. Serial step sections, $4 \mu \mathrm{m}$ in thickness, were taken along the longitudinal axis of the lobe. The fixed distance between the sections was calculated so as to allow approximately 10 sections across the whole lobe. The sections were stained with fuchsin.

The left lung was processed for TEM. It was cut completely into slices of 2-mm thickness perpendicular to the longitudinal axis. From this stack every $n^{\text {th }}$ slice was taken, $n$ being a value calculated to yield approximately four slices from the lobe. These slices were diced into cubes of $2 \times 2 \times 2 \mathrm{~mm}$, and from these blocks 10 were taken at random. Both the LM and TEM sampling procedures fulfilled the requirements of a systematic random protocol (22). The TEM tissue blocks were postfixed for $1 \mathrm{~h}$ in a $1 \% \mathrm{Na}$-cacodylate-buffered $\mathrm{OsO}_{4}$ solution (osmolality $350 \mathrm{mOsm}, \mathrm{pH}$ 7.4). The tissue cubes were then blockcontrasted by immersion in $0.5 \%$ uranyl acetate for $1 \mathrm{~h}$, dehydrated in ascending concentrations of ethanol, and embedded in Epon 812. Five blocks per animal were finally selected, and ultrathin sections $(80-90 \mathrm{~nm}$ ) were cut on a Reichert-Jung Ultracut microtome using a diamond knife; sections were picked up on 200-mesh grids and stained with lead citrate. It had been demonstrated earlier that for quantitative purposes a single lobe of the rat lung was a representative sample of the whole organ (23). Hence, only material obtained from the left lung was used in this TEM investigation.

LM morphometry. For LM morphometry, the paraffin sections of the right middle lobe were analyzed at $\times 400$ magnification on a Wild M 501 motor stage sampling microscope. The sections were projected onto a screen containing a single point test system. The sections were moved in a stepwise manner in the $\mathrm{x}$ and $\mathrm{y}$ directions, while categorizing the underlying structures hit by the test point. The $\mathrm{x}$ and $\mathrm{y}$ step size was adjusted to yield in each lobe approximately 100 test point hits on the structure with the lowest area density.

The volume densities of parenchyma $\left[\mathrm{V}_{\mathrm{Vp}}\right.$ (air spaces and tissue)] and of nonparenchyma $\left[\mathrm{V}_{\mathrm{Vnp}}\right.$ (bronchi, bronchioli, blood vessels $>20 \mu \mathrm{m}$ in diameter, and larger connective tissue strips)] were measured using the whole lobe as reference space. Absolute volumes were calculated for each animal as the product of volume densities for each variable and the respective lung volume.

Electron microscopic morphometry. Five of the 10 blocks per left lung were randomly taken, and one technically perfect section per block was viewed in a Philips EM 200. Eight quadrants per section containing lung tissue were photographed by systematic random sampling (24) and recorded on 35 -mm film at $\times 1,200$ primary magnification. Fields of view containing only air and no tissue were not photographed but were recorded separately and included in the calculations. Positive contact copies of the film were viewed in a projection unit at a final magnification of $\times 12,000$. Volume and surface data were obtained using the STEPone program for morphometry (25). Point and intersection counts were recorded using the M 168 test grid (26). Point counting permitted the assessment of volume fractions, and the intersection counts were used to calculate the surface densities.

The following variables were evaluated: the volume densities of air spaces $\left(\mathrm{V}_{\mathrm{Va}}\right)$, capillaries $\left(\mathrm{V}_{\mathrm{Vc}}\right)$, and tissue $\left[\left(\mathrm{V}_{\mathrm{Vt}}\right)\right.$ consisting of epithelial type I cells $\left(\mathrm{V}_{\mathrm{VepI}}\right)$, epithelial type II cells $\left(\mathrm{V}_{\mathrm{VepII}}\right)$, endothelium $\left(\mathrm{V}_{\mathrm{Ven}}\right)$, and interstitium $\left(\mathrm{V}_{\mathrm{Vi}}\right)$ ]. Furthermore, the surface densities of the air spaces $\left(\mathrm{S}_{\mathrm{Va}}\right.$, interface of type I and II cells to air spaces) and of capillaries $\left(\mathrm{S}_{\mathrm{Vc}}\right.$, interface of endothelium to capillary lumen) were assessed. Absolute and body weight-related (i.e. specific) values for each animal were calculated. In addition several function- 
ally important variables like the arithmetic mean barrier thickness of tissue $\left(\mathrm{T}_{\mathrm{ar}}\right)$, the harmonic mean thickness $\left(\mathrm{T}_{\mathrm{ht}}\right)$, the mean linear intercept $\left(\mathrm{L}_{\mathrm{m}}\right)$, and the pulmonary diffusion capacity $\left(D_{L}\right)$ were computed.

Calculations and statistical analysis. Absolute values for each animal were obtained as the product of relative values $\left(\mathrm{V}_{\mathrm{V}}, \mathrm{S}_{\mathrm{V}}\right)$ and absolute parenchymal volume of the respective lung (i.e. $\mathrm{V}_{\mathrm{V}} \times \mathrm{V}_{\mathrm{L}} \times \mathrm{V}_{\mathrm{Vp}}$ or $\mathrm{S}_{\mathrm{V}} \times \mathrm{V}_{\mathrm{L}} \times \mathrm{V}_{\mathrm{Vp}}$ ). The specific values were computed as the corresponding absolute values per $100 \mathrm{~g}$ body weight.

The arithmetic mean barrier thickness of tissue $\left(\mathrm{T}_{\mathrm{ar}}\right)$ was calculated according to the following equation:

$$
\mathrm{T}_{\mathrm{ar}}=\frac{\mathrm{Vt}}{\mathrm{Sa}+\mathrm{Sc} / 2} .
$$

Furthermore, the harmonic mean thickness $\left(\mathrm{T}_{\mathrm{ht}}\right)$ of the tissue part of the air-blood barrier (epithelium, interstitium, and endothelium together) was measured (27). The mean linear intercept $\left(\mathrm{L}_{\mathrm{m}}\right)$ was calculated from the available intersection counts according to the following formula:

$$
\mathrm{Lm}=2 \cdot \frac{l_{\text {tot }}}{I x}
$$

where $l_{\text {tot }}$ is the total length of all test lines and $I x$ the number of intersections of these lines with the air-tissue interface. Furthermore, the pulmonary diffusion capacity for oxygen $\left(\mathrm{D}_{\mathrm{LO} 2}\right)$ was calculated as absolute and specific values, based on the morphometric model described by Weibel et al. (27). We adapted the formula of the model to include only the solid tissue barrier of the septa and excluded the plasma layer, because the latter is heavily influenced by the heart action during lung fixation. The following formulas were used:

$$
1 / \mathrm{DLO}_{\mathrm{x}}=1 / \mathrm{DtO}_{2}+1 / \mathrm{DeO}_{2}
$$

where $\mathrm{DtO}_{2}$ and $\mathrm{DeO}_{2}$ represent the diffusion capacities of the tissue barrier and the erythrocytes, respectively.

$$
1 / \mathrm{DtO}_{2}=\mathrm{K}_{\mathrm{b}} \cdot(\mathrm{Sa}+\mathrm{Sc}) /\left(2 \mathrm{~T}_{\mathrm{ht}}\right.
$$

where $\mathrm{K}_{\mathrm{b}}$ is the Krogh diffusion constant assumed to be $3.3 \times$ $10^{-8} \mathrm{~cm}^{2} \cdot \mathrm{min}^{-1} \cdot \mathrm{mm} \mathrm{Hg}^{-1}$ (27).

$$
\mathrm{De}_{\mathrm{O} 2}=\Theta_{\mathrm{O} 2} * \mathrm{Vc}
$$

where $\Theta_{\mathrm{O} 2}$ is the rate of $\mathrm{O}_{2}$ uptake by the whole blood, which was calculated as $7.158 \times$ hematocrit (27).

Means and standard errors were calculated for each group. The results are presented as mean \pm 1 SEM of the group. Statistical comparisons between groups were made using a nonparametric two-tailed Wilcoxon test. Values for $p<0.05$ were considered statistically significant.

\section{RESULTS}

\section{Lung Morphology}

The most remarkable changes between the lungs of the treated animals and age-matched controls were apparent at postnatal $\mathrm{d} 4$ and 21. Structural differences were inconspicuous by $\mathrm{d} 36$, and by $\mathrm{d} 60$ the lungs of the two groups were structurally and morphometrically indistinguishable.
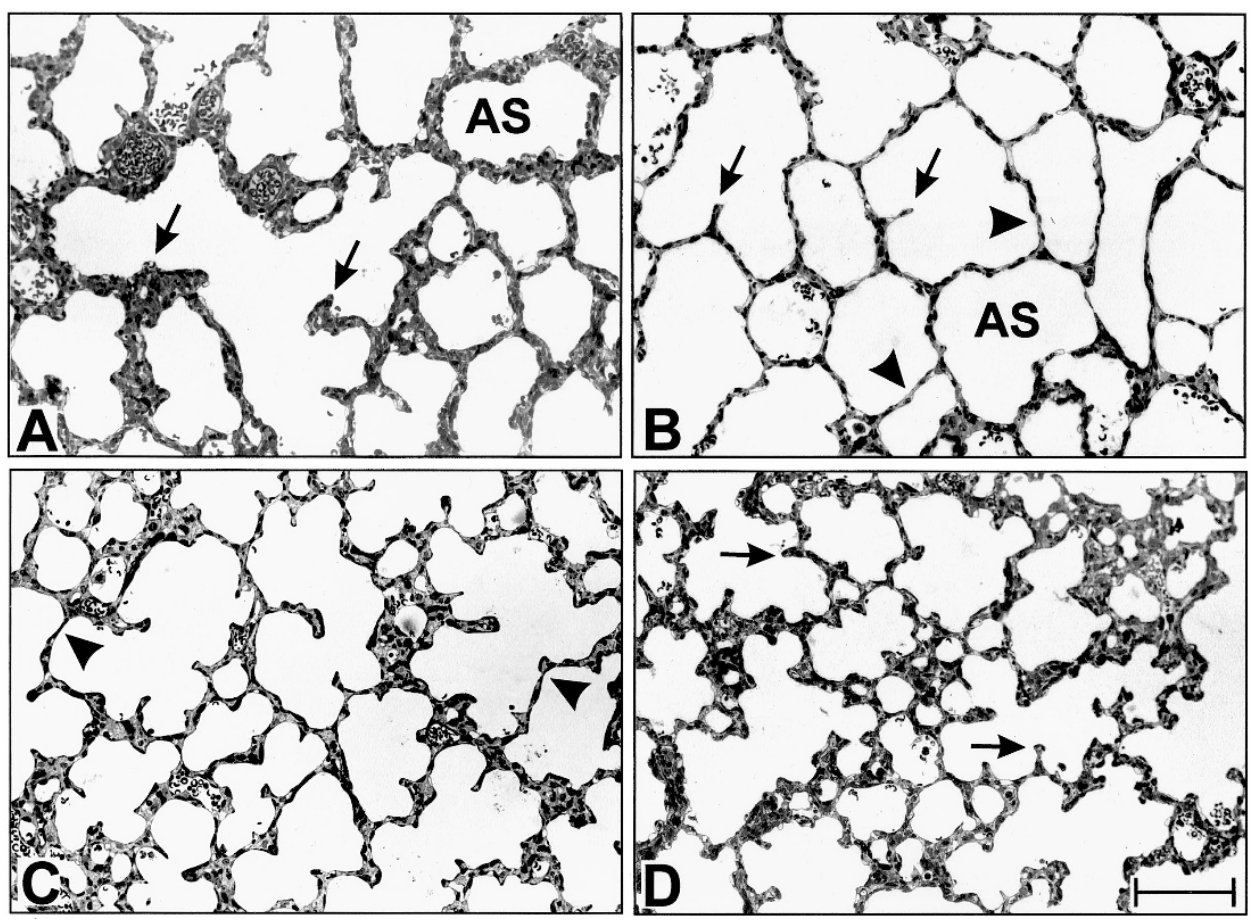

Figure 1. Light micrographs of rat lung parenchyma at postnatal d 4 and 10 showing the effects of dexamethasone therapy. In control rats $(A)$ at $\mathrm{d} 4$, the septa are thick and have an appreciable number of sprouting crests (arrows) and air spaces are of normal size. In the treated rats $(B)$, the septa are much thinner (arrowheads), secondary crests are scanty (arrows) and the air spaces $(A S)$ are much larger. In control rats $(C)$ at $\mathrm{d} 10$, the septa are relatively thinner (arrowheads), and air spaces are larger compared with the treated rats $(D)$, in which the septa are thicker, sprouting secondary crests are numerous (arrows) and the air spaces are generally much smaller in size. Bar, $100 \mu \mathrm{m}$. 
At $\mathrm{d} 4$, the most dramatic differences in the entire experiment were recognized, and these consisted of thinner inter-air space septa, larger and fewer air spaces, and a reduction in the number of sprouting secondary septa in the treated animals (Fig. 1, $A$ and $B$ ). The $\mathrm{LM}$ observations at $\mathrm{d} 10$ revealed a tendency to a reversal of the situation seen at $\mathrm{d}$ 4: the treated animals showed slightly thicker septa and a preponderance of short, sprouting secondary septa (Fig. 1, $C$ and $D$ ). The air spaces in the latter group also appeared relatively smaller and less homogeneous in size and also more numerous. From postnatal d 21, no further differences were recognizable at the LM level.

At the ultrastructural level, lungs in the control animals at $\mathrm{d}$ 4 had wide areas showing a double capillary layer whereas in the treated group, a single capillary network was predominant (Fig. 2, $A$ and $B$ ). The interstitial tissue was also more abundant in the control than in the treated animals. By d 10, the situation was reversed and the lungs of the treated animals showed a preponderance of thicker septa with a double capillary network and plentiful interstitial tissue (Fig. 2, $C$ and $D$ ). The double capillary system was sparse in the control group, the septa were thin, and the interstitial tissue was scanty (Fig. 2A). By the 21st postnatal day, the lungs in both groups showed a single capillary system (Fig. 3, $A$ and $B$ ), the only difference being that the septa in the treated animals appeared more irregular and rugged with capillary profiles tending to bulge out of the general septal surface (Fig. 3B) whereas those of the control group were rather smooth (Fig. 3A). At postnatal d 36 and 60 (Fig. 4) no structural differences could be made out.

\section{Morphometry}

Morphometric data are presented in Tables 1- 4 .

Body weights and lung volumes. The base data for dexamethasone-treated (GC) and control animals are listed in Table 1. The variances in body weight and lung volume within age groups were rather small. Significant differences in body weights were detectable on $\mathrm{d} 21$ with a $12 \%$ decrease in treated animals, on d 36 with an $8 \%$ increase, and on d 60 with an $11 \%$ decrease, again, all versus control animals. The lung volume was only significantly different on $\mathrm{d} 21$, when the body weightspecific volume was higher by $12 \%$ in the GC group.

Absolute lung volume appeared to be elevated in GC-treated rats only at $36 \mathrm{~d}$ of age (Table 1). However, body weightnormalized lung volume appeared to be increased by GC treatment as early as postnatal d 21 . The latter may be exaggerated by the depression in weight observed in the treated animals. As expected, body weight-normalized lung volume decreased gradually with age in both groups, being lowest in adults.

Alterations in the nonparenchyma and its components. At the LM level, the volume of nonparenchyma of the lung (bronchi, larger vessels, and pleural structures) was significantly depressed at d $4(-27 \%)$ in GC animals (Table 1), mainly consisting of a significant reduction of large vessel volume $(-43 \%)$ and of coarse connective tissue volume ( $-54 \%$; data not shown). However, by d 21 , GC treatment appeared to boost development of the nonparenchyma, so that
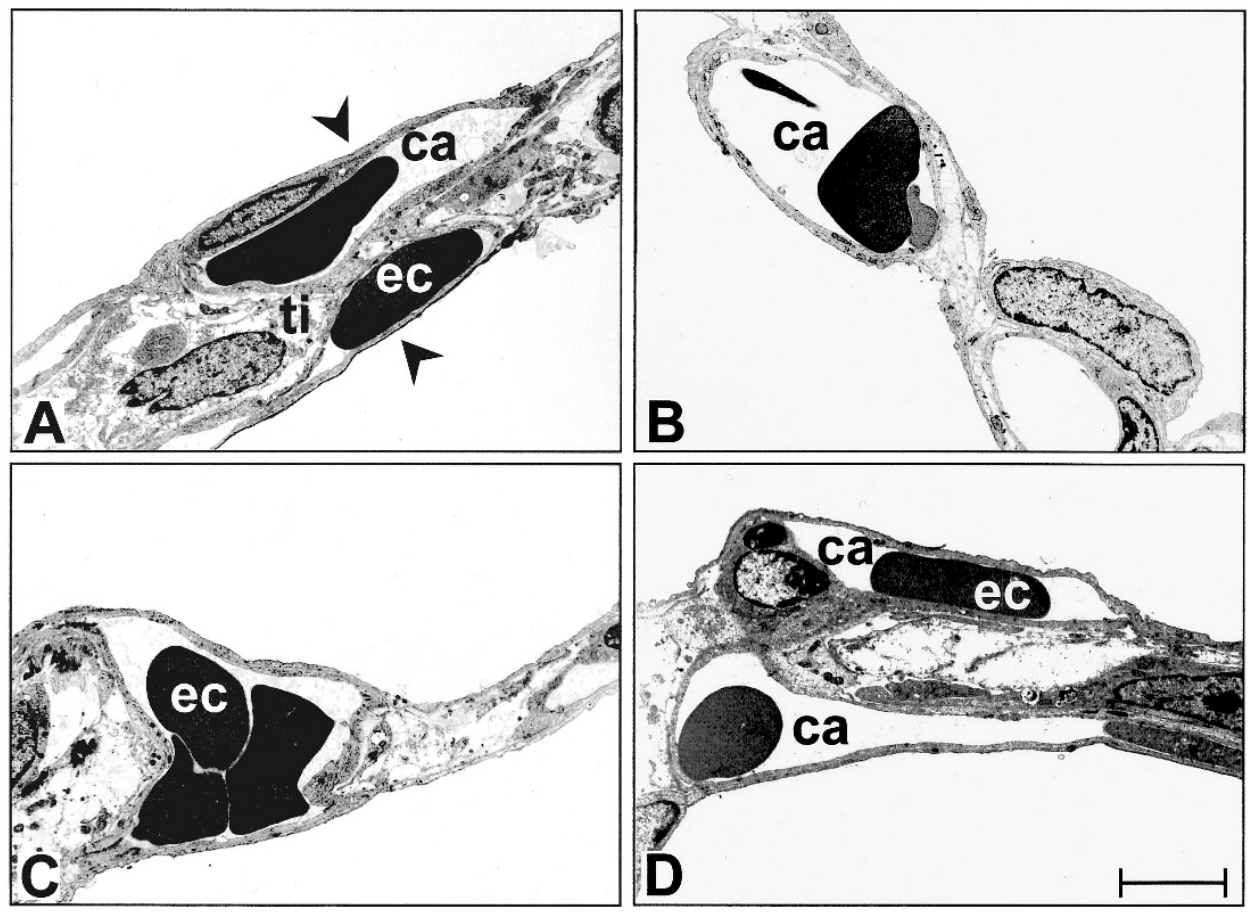

Figure 2. Transmission electron micrographs of the interalveolar septa of the rat lung at postnatal d 4 and 10 showing the effects of dexamethasone therapy on lung maturation. In control rats $(A)$ at $\mathrm{d} 4$, the septa are thick and have plentiful interstitial tissue $(t i)$ and a prominent double capillary system (arrowheads) containing erythrocytes $(e c)$, whereas in the treated rats $(B)$, the septa are much thinner with scanty interstitial tissue, and a single capillary system $(c a)$ is the more preponderant type. In control rats $(C)$ at d 10 , the septa are relatively thinner compared with the treated rats $(D)$, in which the septa are thick with plentiful interstitial tissue and the double capillary system $(c a)$ is more pronounced. Bar, $5 \mu \mathrm{m}$. 

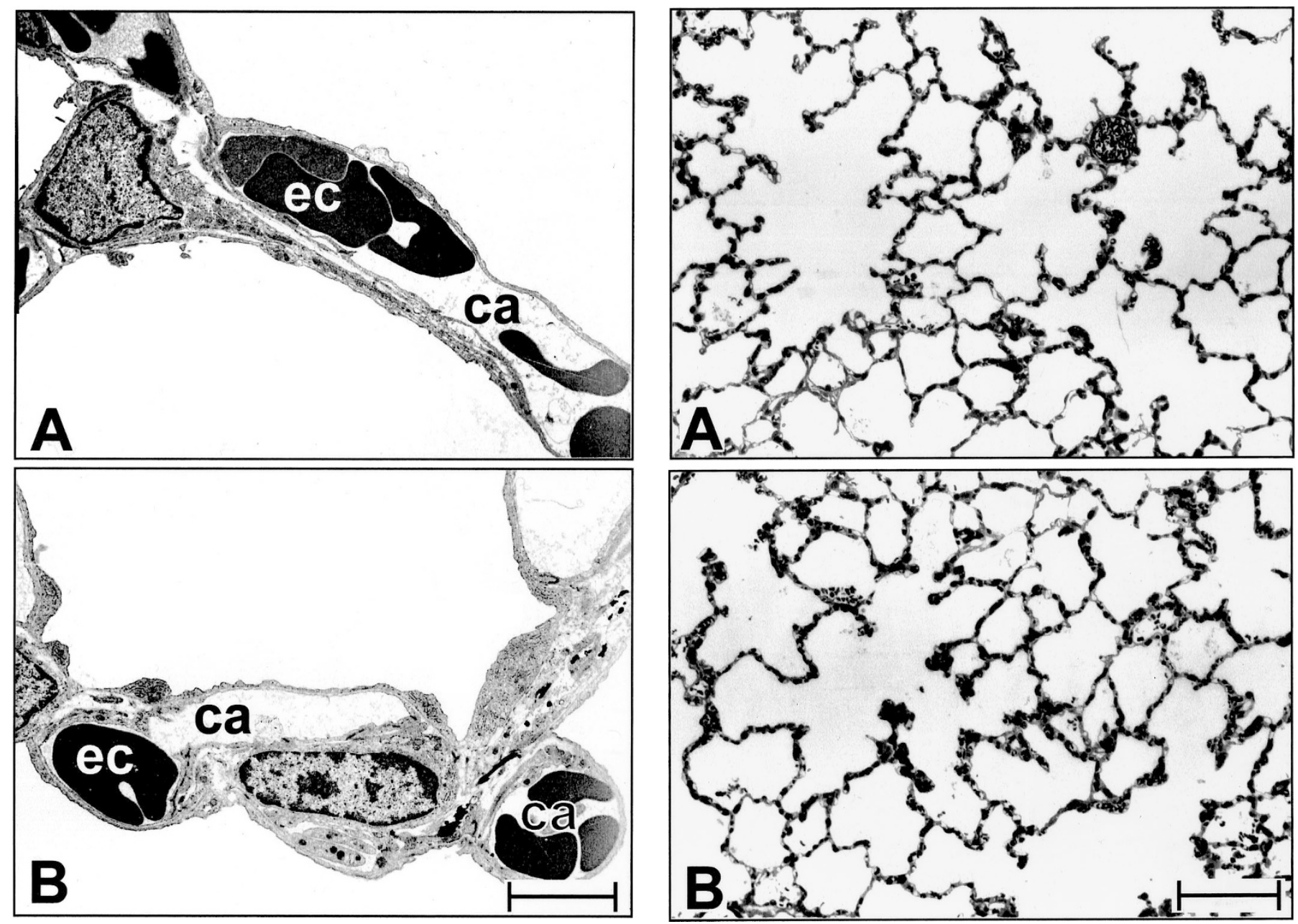

Figure 3. Transmission electron micrographs showing the interalveolar septa at postpartum $\mathrm{d} 21$. In control rats $(A)$, the septa appear thinner and much smoother, with a single capillary system $(\mathrm{ca})$ on one side of the septum, whereas in the treated animals $(B)$, the septa are rugged and irregular, and the capillaries $(c a)$ containing erythrocytes $(e c)$ tend to bulge into the alveolar lumina. Bar, $5 \mu \mathrm{m}$.

$\mathrm{V}_{\mathrm{np}}$ was back to control values. The nonparenchymal density was highest in young animals and lowest in adults, but in all cases it did not exceed $20 \%$ (Table 1).

Alterations in the parenchyma and its components: volumes. The parenchymal volume density was increased by GC treatment by $\mathrm{d} 4$ and was back to control level by the time alveolarization was complete (d 21; Table 1), and did not deviate further from control values.

The parenchyma is made up of the gas exchange air spaces and the septa (Tables 2 and 3). The septal components include the epithelium, comprising type I and II pneumocytes, the interstitium, and the capillary endothelial and luminal components (Tables 2 and 3). On postnatal d 4 the absolute septal volume was decreased by $22 \%$ in the treated animals. This change was caused mainly by an absolute volume decrease of interstitium $(-32 \%)$ and of endothelium $(-32 \%)$. The epithelial component of the septum was only slightly decreased at this age, but interestingly this resulted from a slight increase of the type I pneumocyte volume and a more marked decrease in type II cell volume. Both values did not, however, reach

Figure 4. Light micrographs of rat lung parenchyma at d 60 postpartum. $A$, control animal; $B, \mathrm{GC}$ animal. No visual differences were observed between groups. Bar, $100 \mu \mathrm{m}$.

statistical significance. The septal tissue volume was significantly decreased by $24.6 \%$ in the treated group.

At $d 4$ the capillary volume consisting of plasma and erythrocytes showed a trend toward slightly lower values in the experimental group, but the changes did not reach statistical significance. By postnatal d 10, however, both the endothelial and capillary volumes were significantly elevated after GC treatment. As expected, because it is complementary to septal tissue, the volume of parenchymal air spaces tended to be higher in the treated animals, but did not reach statistical significance.

Alterations in the parenchyma: surface areas, barrier thicknesses, and diffusion capacities. The surface area of air spaces was significantly increased (24\%) in treated animals by d 4 postpartum (Table 4). Conversely the surface area of capillaries was decreased by $32 \%$ by d 4 but appeared to be mildly boosted by GC treatment at all the subsequent ages tested.

On d 4, the arithmetic mean barrier thickness in GC-treated animals was markedly decreased by $34 \%$, perfectly matching the changes in septal structure. However, the harmonic mean barrier thickness was not changed. The morphometrically es- 
Table 1. Base parameters

\begin{tabular}{|c|c|c|c|c|c|c|c|c|c|c|}
\hline & \multicolumn{2}{|c|}{$\begin{array}{c}\text { Body weight } \\
\text { (BW) [g] }\end{array}$} & \multicolumn{2}{|c|}{$\begin{array}{l}\text { Lung volume } \\
\left(\mathrm{V}_{\mathrm{L}}\right)\left[\mathrm{cm}^{3}\right]\end{array}$} & \multicolumn{2}{|c|}{$\begin{array}{l}\text { Volume density } \\
\text { of parenchyma } \\
\left(\mathrm{V}_{\mathrm{Vp}}\right) \text { ratio }\end{array}$} & \multicolumn{2}{|c|}{$\begin{array}{c}\text { Parenchymal } \\
\text { volume }\left(\mathrm{V}_{\mathrm{p}}\right)\left[\mathrm{cm}^{3}\right] \\
\end{array}$} & \multicolumn{2}{|c|}{$\begin{array}{l}\text { Non-parenchymal } \\
\text { volume }\left(\mathrm{V}_{\mathrm{pnp}}\right)\left[\mathrm{cm}^{3}\right]\end{array}$} \\
\hline & $\overline{\mathrm{X}}$ & SEM & $\overline{\mathrm{X}}$ & SEM & $\overline{\mathrm{X}}$ & SEM & $\overline{\mathrm{X}}$ & SEM & $\overline{\mathrm{X}}$ & SEM \\
\hline \multicolumn{11}{|l|}{ Day 4} \\
\hline Control & 13.1 & 0.4 & 1.03 & 0.03 & 0.816 & 0.010 & 0.840 & 0.028 & 0.189 & 0.011 \\
\hline Dexa & 12.6 & 0.4 & 1.01 & 0.05 & 0.862 & $0.007 * *$ & 0.870 & 0.043 & 0.139 & $0.009 * *$ \\
\hline \multicolumn{11}{|l|}{ Day 10} \\
\hline Dexa & 24.5 & 0.4 & 1.73 & 0.06 & 0.878 & $0.003^{*}$ & 1.519 & 0.053 & 0.211 & 0.012 \\
\hline \multicolumn{11}{|l|}{ Day 21} \\
\hline Control & 79.2 & 2.0 & 3.61 & 0.15 & 0.872 & 0.005 & 3.151 & 0.144 & 0.461 & 0.015 \\
\hline Dexa & 69.3 & $0.8^{*}$ & 3.53 & 0.08 & 0.864 & 0.004 & 3.051 & 0.074 & 0.479 & 0.016 \\
\hline \multicolumn{11}{|l|}{ Day 36} \\
\hline Control & 209.0 & 4.0 & 7.28 & 0.22 & 0.852 & 0.006 & 6.200 & 0.159 & 1.082 & 0.071 \\
\hline
\end{tabular}

$\mathrm{SEM}=$ Standard error of mean. Values are means of groups of $n=5$ animals.

Significance level: $* p<0.05 ; * *<0.01$.

Table 2. Volume and surface densities

\begin{tabular}{|c|c|c|c|c|c|c|c|c|c|c|c|c|}
\hline & \multicolumn{2}{|c|}{$\begin{array}{c}\text { Volume density } \\
\text { of air spaces } \\
\left(\mathrm{V}_{\mathrm{Va}}\right)\end{array}$} & \multicolumn{2}{|c|}{$\begin{array}{l}\text { Volume density } \\
\text { of septa } \\
\left(\mathrm{V}_{\mathrm{Vs}}\right)\end{array}$} & \multicolumn{2}{|c|}{$\begin{array}{l}\text { Volume density } \\
\text { of epithelium } \\
\left(\mathrm{V}_{\mathrm{Vep}}\right)\end{array}$} & \multicolumn{2}{|c|}{$\begin{array}{l}\text { Volume density } \\
\text { of interstitium } \\
\left(\mathrm{V}_{\mathrm{Vi}}\right)\end{array}$} & \multicolumn{2}{|c|}{$\begin{array}{l}\text { Volume density } \\
\text { of endothelium } \\
\left(\mathrm{V}_{\mathrm{Ven}}\right)\end{array}$} & \multicolumn{2}{|c|}{$\begin{array}{c}\text { Volume density } \\
\text { of capillary } \\
\text { lumen }\left(\mathrm{V}_{\mathrm{V}_{\mathrm{c}}}\right)\end{array}$} \\
\hline \multicolumn{13}{|l|}{ Day 4} \\
\hline Control & 0.726 & 0.015 & 0.274 & 0.015 & 0.042 & 0.004 & 0.136 & 0.014 & 0.031 & 0.002 & 0.064 & 0.005 \\
\hline Dexa & 0.794 & $0.017^{* *}$ & 0.206 & $0.017^{* *}$ & 0.039 & 0.003 & 0.090 & $0.010^{*}$ & 0.021 & $0.001 * *$ & 0.056 & 0.004 \\
\hline Dexa & 0.714 & 0.021 & 0.286 & 0.021 & 0.033 & 0.002 & 0.150 & 0.014 & 0.038 & 0.002 & 0.065 & 0.005 \\
\hline \multicolumn{13}{|l|}{ Day 21} \\
\hline Control & 0.824 & 0.020 & 0.176 & 0.020 & 0.030 & 0.003 & 0.047 & 0.007 & 0.026 & 0.002 & 0.073 & 0.013 \\
\hline Dexa & 0.792 & 0.019 & 0.208 & 0.019 & 0.035 & 0.001 & 0.073 & $0.005^{*}$ & 0.024 & 0.002 & 0.075 & 0.014 \\
\hline \multicolumn{13}{|l|}{ Day 36} \\
\hline Control & 0.805 & 0.008 & 0.195 & 0.008 & 0.032 & 0.003 & 0.051 & 0.005 & 0.025 & 0.001 & 0.087 & 0.002 \\
\hline
\end{tabular}

$\mathrm{SEM}=$ Standard error of mean. Values are means of groups of $n=5$ animals.

Significance level: $* p<0.05 ; * * p<0.01$.

timated pulmonary diffusion capacity was not significantly different at any age investigated but was decreased by $19 \%$ at d 4 .

\section{DISCUSSION}

In the rat lung alveolarization starts around postnatal $\mathrm{d} 4$ with the emergence of ridges on the walls of the pulmonary sacculi termed primary septa. The formation of these secondary crests or septa, which represent the future interalveolar walls, depends on the existence of two layers of capillaries in the primary or "mother" septum (28). Alveolarization is a very fast process and leads to a massive increase in gas exchange surface area (20). After this period of approximately $10 \mathrm{~d}$, called bulk alveolarization, the lung enters the stage of microvascular maturation, in which merging and fusion of capillaries result in a septum characterized by a monolayered vascular system typical for the mature adult lung. Evidently, microvascular maturation prevents further alveolar formation.

The present study in rats shows that high-dose short-term treatment with GCs before alveolarization does perturb lung growth and development, but does not (as was found in other treatment schemes) permanently alter parenchymal lung structure. It appears that as early as d 4 , after only $4 \mathrm{~d}$ of treatment, a precocious microvascular maturation of the parenchymal septa resulted in an initial arrest of septation. This acceleration of lung development was, however, rapidly followed by a neotenic step back in pulmonary maturity, allowing a recovery in alveolar formation and ultimately a reversion to normal structure. These GC-induced alterations are consistent with our previous findings (17), with the difference, though, that in the latter study, no recovery of the impairments was realized. 
Table 3. Parenchymal components

\begin{tabular}{|c|c|c|c|c|c|c|c|c|c|c|c|c|}
\hline & \multicolumn{2}{|c|}{$\begin{array}{c}\text { Airspace volume } \\
\left(\mathrm{V}_{\mathrm{a}}\right)\left[\mathrm{cm}^{3}\right]\end{array}$} & \multicolumn{2}{|c|}{$\begin{array}{l}\text { Septal volume } \\
\left(\mathrm{V}_{\mathrm{s}}\right)\left[\mathrm{cm}^{3}\right]\end{array}$} & \multicolumn{2}{|c|}{$\begin{array}{c}\text { Volume } \\
\text { epithelium type } \\
1 \& 2\left(\mathrm{~V}_{\mathrm{ep}}\right)\left[\mathrm{cm}^{3}\right]\end{array}$} & \multicolumn{2}{|c|}{$\begin{array}{c}\text { Interstitial } \\
\text { volume }\left(\mathrm{V}_{\mathrm{i}}\right) \\
\quad\left[\mathrm{cm}^{3}\right]\end{array}$} & \multicolumn{2}{|c|}{$\begin{array}{c}\text { Endothelial } \\
\text { volume }\left(\mathrm{V}_{\mathrm{en}}\right) \\
{\left[\mathrm{cm}^{3}\right]}\end{array}$} & \multicolumn{2}{|c|}{$\begin{array}{c}\text { Capillary volume } \\
\qquad\left(\mathrm{V}_{\mathrm{c}}\right)\left[\mathrm{cm}^{3}\right]\end{array}$} \\
\hline & $\overline{\mathrm{X}}$ & SEM & $\overline{\mathrm{X}}$ & SEM & $\overline{\mathrm{X}}$ & SEM & $\overline{\mathrm{X}}$ & SEM & $\overline{\mathrm{X}}$ & SEM & $\bar{X}$ & SEM \\
\hline \multicolumn{13}{|l|}{ Day 4} \\
\hline Control & 0.611 & 0.029 & 0.229 & 0.010 & 0.035 & 0.003 & 0.113 & 0.010 & 0.026 & 0.002 & 0.081 & 0.007 \\
\hline Dexa & 0.692 & 0.043 & 0.178 & $0.013 * *$ & 0.034 & 0.003 & 0.077 & $0.007 *$ & 0.018 & $0.001 * *$ & 0.067 & 0.004 \\
\hline Dexa & 1.088 & 0.067 & 0.431 & 0.021 & 0.050 & 0.002 & 0.226 & 0.016 & 0.057 & 0.001 & 0.155 & 0.006 \\
\hline \multicolumn{13}{|l|}{ Day 21} \\
\hline Control & 2.594 & 0.127 & 0.557 & 0.073 & 0.093 & 0.009 & 0.148 & 0.022 & 0.082 & 0.009 & 0.316 & 0.053 \\
\hline Dexa & 2.412 & 0.041 & 0.639 & 0.068 & 0.106 & 0.003 & 0.224 & $0.018^{*}$ & 0.075 & 0.008 & 0.309 & 0.053 \\
\hline \multicolumn{13}{|l|}{ Day 36} \\
\hline Control & 4.992 & 0.161 & 1.207 & 0.038 & 0.197 & 0.015 & 0.315 & 0.026 & 0.153 & 0.008 & 0.696 & 0.025 \\
\hline
\end{tabular}

$\mathrm{SEM}=$ Standard error of mean. Values are means of groups of $n=5$ animals.

Significance level: $* p<0.05 ; * *<0.01$.

Table 4. Surface areas and functional parameters

\begin{tabular}{|c|c|c|c|c|c|c|c|c|c|c|c|c|c|c|}
\hline & \multicolumn{2}{|c|}{$\begin{array}{c}\text { Surface area } \\
\text { density of air } \\
\text { space }\left(\mathrm{S}_{\mathrm{Va}}\right) \\
{\left[\mathrm{cm}^{2} / \mathrm{cm}^{3}\right]}\end{array}$} & \multicolumn{2}{|c|}{$\begin{array}{c}\text { Surface area } \\
\text { of air spaces } \\
\left(\mathrm{S}_{\mathrm{a}}\right)\left[\mathrm{cm}^{2}\right]\end{array}$} & \multicolumn{2}{|c|}{$\begin{array}{c}\text { Surface area } \\
\text { density of } \\
\text { capillaries } \\
\left(\mathrm{S}_{\mathrm{Vc}}\right) \\
{\left[\mathrm{cm}^{2} / \mathrm{cm}^{3}\right]}\end{array}$} & \multicolumn{2}{|c|}{$\begin{array}{c}\text { Surface area } \\
\text { of capillaries } \\
\left(\mathrm{S}_{\mathrm{c}}\right)\left[\mathrm{cm}^{2}\right]\end{array}$} & \multicolumn{2}{|c|}{$\begin{array}{c}\text { Arithmetic } \\
\text { mean barrier } \\
\text { thickness }\left(\mathrm{T}_{\text {arr }}\right) \\
{[\mu \mathrm{m}]}\end{array}$} & \multicolumn{2}{|c|}{$\begin{array}{c}\text { Harmonic } \\
\text { mean barrier } \\
\text { thickness }\left(\mathrm{T}_{\mathrm{h}}\right) \\
{[\mu \mathrm{m}]}\end{array}$} & \multicolumn{2}{|c|}{$\begin{array}{l}\text { Pulmonary diffusion } \\
\text { capacity }\left(\mathrm{DLO}_{2}\right) \\
{\left[\mathrm{ml} \mathrm{O}_{2} / \mathrm{min} / \mathrm{mmHg}\right]}\end{array}$} \\
\hline & $\bar{X}$ & SEM & $\bar{X}$ & SEM & $\overline{\mathrm{X}}$ & SEM & $\overline{\mathrm{X}}$ & SEM & $\overline{\mathrm{X}}$ & SEM & $\overline{\mathrm{X}}$ & SEM & $\overline{\mathrm{X}}$ & SEM \\
\hline \multicolumn{15}{|l|}{ Day 4} \\
\hline \multicolumn{15}{|l|}{ Day 10} \\
\hline Control & 590 & 40 & 916 & 73 & 677 & 91 & 1079 & 189 & 4.87 & 0.27 & 0.65 & 0.03 & 0.151 & 0.030 \\
\hline Dexa & 599 & 31 & 910 & 57 & 737 & 20 & 1117 & 32 & 4.79 & 0.20 & 0.61 & 0.04 & 0.163 & 0.012 \\
\hline \multicolumn{15}{|l|}{ Day 21} \\
\hline Control & 849 & 73 & 2652 & 202 & 498 & 41 & 1578 & 170 & 1.46 & 0.11 & 0.45 & 0.02 & 0.491 & 0.089 \\
\hline Dexa & 1042 & $49^{*}$ & 3171 & $123^{*}$ & 525 & 57 & 1617 & 202 & 1.59 & 0.09 & 0.43 & 0.04 & 0.541 & 0.110 \\
\hline Dexa & 810 & 46 & 6941 & 332 & 535 & 26 & 4597 & 240 & 1.21 & 0.06 & 0.52 & 0.02 & 1.607 & 0.110 \\
\hline
\end{tabular}

SEM $=$ Standard error of mean. Values are means of groups of $n=5$ animals.

Significance level: $* p<0.05 ; * * p<0.01$.

The reduction of septal thickness in GC animals at $\mathrm{d} 4$ (Fig. 2 ) is a typical sign of microvascular maturation. Inasmuch as this process occurred precociously in these rats, the process of alveolarization was inhibited, albeit temporarily. The thinning of the interalveolar septa was the result of a reduction in the volume of the interstitial tissue mainly, but also of all the components of the septum, as reflected in the morphometric findings. Reduction of the interstitium involves apoptosis of fibroblasts (29) and also a diminution in the mass of interstitial fibers and ground substance by yet unknown mechanisms (30). Rarefaction of the interstitium invariably brings the two layers of the double capillary network into close contact, thus inducing the subsequent fusion (28) - an event that terminates further septation of the air spaces (31). Reduction in the thickness of the epithelial component of the septa entails apoptosis of type II cells (30), as well as their conversion into squamous pneumocytes of type I and attenuation of the latter (32). The mechanisms through which GCs promote thinning of the interalveolar septa are not clearly understood, but it is known that GCs inhibit fibroblast proliferation (33) and, as a consequence, interfere with interstitial matrix production.

In contrast to the changes in septal structure, the geometric pattern of the inter-air space septa in the section plane was not changed much (Fig. 1, $A$ and $B$ ), a fact supported by findings of Schwyter et al. (34) by analyzing the skeleton variables of lung sections of treated and control animals. Nevertheless, the morphometrically estimated pulmonary diffusion capacity was decreased in experimental animals, indicating that GCs did not improve the morphologic functional capacity of the lung. 
By d 10 postpartum, the situation appeared to be reversed. The variables assessing the septal microvasculature in GCtreated animals were shifted toward immaturity. In addition to a higher mass of interstitial tissue, the overall volume of the septa was increased, which resulted in thicker septa. This developmental step back was even more prominent on d 21, when the interstitial tissue volume was markedly and significantly increased. Although in normal rats the process of bulk alveolarization practically ends after 2 wks and by d 21 most parenchymal regions are mature regarding the vascular system, lung parenchyma from GC-treated animals still looked immature. Our findings on $\mathrm{d} 10$ and 21 were highly suggestive of compensatory reparative processes comparable to those seen in the long-term low-dose study mentioned before (17). In this latter study similar reparative attempts were observed at $3 \mathrm{wk}$ of age after withdrawal of long-term low-dose GC administration. Those compensatory mechanisms were not able, however, to achieve a complete recovery of the lung morphologic phenotype and to avoid permanent alterations in the lung structure.

At postnatal d 21 there was a significant increase in absolute and body weight-normalized surface area of the air spaces. Accordingly, we observed a tendency for improvement in the morphometrically assessed $\mathrm{O}_{2}$ diffusion capacity in GC-treated animals, which was already initiated on $\mathrm{d} 10$. This observation is somehow difficult to interpret, all the more so because LM revealed an almost identical complexity of the septal network. The most probable explanation lies in the different quantitative surface detection process at the TEM and LM levels owing to the differences in magnification and resolution. An increase in roughness at the fine structural level in the GC group could account for a marked increase of the surface area at higher magnification (TEM level; Fig. 3). An increased septal tissue volume, including the volume of lung epithelial cells in treated animals, could also contribute to the ruggedness of the septal surface. The increase in septal tissue mass in GC animals at 3 wk of age is a strong hint of the growth and differentiation processes, which are signs of extant reparative mechanisms. Normally, by postnatal d 21 in rat lung development, most maturational events including microvascular maturation are already completed.

The results obtained in the oldest two groups in our experiment revealed two important facts: first, after the rather significant alterations of lung structure early after GC administration, we observed only minor changes in the fine structure of the parenchyma on d 36 and a complete recovery to normal values by $\mathrm{d} 60$. This involved mainly an increase in the volume of parenchyma, owing to a higher air space volume. Second, the body weight of GC-treated animals was significantly increased at d 36 and decreased at $\mathrm{d} 60$. From these findings we deduce that, on the one hand, the organism disposes of compensatory mechanisms, which allow the lung to recover from an early GC-inflicted damage. On the other hand, it appears that $\mathrm{GC}$ treatment influences the timing and duration of the normally occurring growth phases. Such a "dephasing" of general body growth has also been shown to occur in lung regeneration experiments (35).

This study underscores that dosage and timing of GC administration is important regarding the drug's adverse effects on the lung. Most results presented so far demonstrated longlasting effects of GC in rats and have implied that the observed inhibition of alveolarization was definitive $(12,13,17,33,36)$. Massaro and Massaro (12) treated rats with minute doses of dexamethasone during a period of approximately $2 \mathrm{wks}$, and similar schemes have been used in the studies of Sahebjami and Domino (13) and in our own earlier investigation (17). Evidently, the schedules of lung development in rats and humans are different, both in time and quantity. The individual phases of lung development with their structural mechanisms and alterations are, however, quite comparable in many mammals. In the rat, alveolarization begins at $4 \mathrm{~d}$ after birth and bulk formation lasts until postnatal d 13. A treatment beginning in the first days after birth in rats starts therefore at the end of the saccular stage. In human neonatology, in which postnatal GC treatment is mostly given to preterm babies, we face a very similar situation: the babies' lungs also are in the saccular phase. In humans alveolar formation starts some weeks before normal birth. A treatment of 10 to $12 \mathrm{~d}$ duration in rats (like in the studies mentioned above) covers the whole period of bulk alveolar formation. In humans, this would correspond at least to the first 6 mo of life.

\section{CONCLUSION}

It is obvious that $\mathrm{GC}$ treatment influences lung development and maturation in many ways; it also influences body growth and its phases and most likely also development and growth of other organs. Our study shows that the lung has the potential to recover to varying degrees from the harmful GC effects depending on timing and dosage of drug application. We therefore believe that optimization of dosage and duration of GC treatment are key elements in reducing its negative effects on the lung parenchyma - duration probably being more important than dosage of the drug. We conclude from our experiments in postnatal rats that short-term high-dose GC administration has less adverse effects regarding lung development than a long-term low-dose scheme.

Acknowledgments. The authors thank Elisabeth de Peyer, Marianne Hofstetter, Christoph Lehmann, and Karl Babl for their technical assistance.

\section{REFERENCES}

1. Avery ME 1995 Historical overview of antenatal steroid use. Pediatrics 95:133-135

2. Hitchcock KR 1980 Lung development and the pulmonary surfactant system: hormonal influences. Anat Rec 198:13-34

3. Buckingham S, Sommers SC, McNary WF 1968 Experimental respiratory distress syndrome. Biol Neonate 12:261-281

4. Anderson WR 1990 Bronchopulmonary dysplasia: a correlative study by light scanning, and transmission electron microscopy. Ultrastruct Pathol 14:221-232

5. Thurlbeck WM 1979 Morphologic aspects of bronchopulmonary dysplasia. J Pediatr 95:842-843

6. Wang JY, Yeh TF, Lin YJ, Chen WY, Lin CH 1997 Early postnatal dexamethasone therapy may lessen lung inflammation in premature infants with respiratory distress syndrome on mechanical ventilation. Pediatr Pulmonol 23:193-197

7. Yeh TF, Torre JA, Rastogi A, Anyebuno MA, Pildes RS 1990 Early postnatal dexamethasone therapy in premature infants with severe respiratory distress syndrome: a double-blind, controlled study. [see comments] J Pediatr 117:273-282

8. Davis JM, Whitin J 1992 Prophylactic effects of dexamethasone in lung injury caused by hyperoxia and hyperventilation. J Appl Physiol 72:1320-1325

9. Kari MA, Heinonen K, Ikonen RS, Koivisto M, Raivio KO 1993 Dexamethasone treatment in preterm infants at risk for bronchopulmonary dysplasia. Arch Dis Child 68:566-569 
10. Silverman M 1989 Long-term lung function is unaffected by antenatal dexamethasone treatment. [letter; comment] Pediatr Pulmonol 6:210-211

11. O'Shea TM, Kothadia JM, Klinepeter KL, Goldstein DJ, Jackson B, Dillard RG 1993 Follow-up of preterm infants treated with dexamethasone for chronic lung disease. Am J Dis Child 147:658-661

12. Massaro D, Massaro GD 1986 Dexamethasone accelerates postnatal alveolar wall thinning and alters wall composition. Am J Physiol 251:R218-R224

13. Sahebjami H, Domino M 1989 Effects of postnatal dexamethasone treatment on development of alveoli in adult rats. Exp Lung Res 15:961-973

14. Doyle L, Davis P 2000 Postnatal corticosteroids in preterm infants: systematic review of effects on mortality and motor function. J Paediatr Child Health 36:101-107

15. Edwards HE, Burnham WM 2001 The impact of corticosteroids on the developing animal. Pediatr Res 50:433-440

16. Barrington KJ 2001 Postnatal steroids and neurodevelopmental outcomes: a problem in the making. Pediatrics 107:1425-1426

17. Tschanz SA, Damke BM, Burri PH 1995 Influence of postnatally administered glucocorticoids on rat lung growth. Biol Neonate 68:229-245

18. Tschanz SA, Haenni B, Burri PH 2002 Glucocorticoid induced impairment of lung structure assessed by digital image analysis. Eur J Pediatr 161:26-30

19. Burri PH 1999 Lung development and pulmonary angiogenesis. In: Gaultier C, Bourbon J, Post M (eds) Lung Development. Oxford University Press, New York, pp 122-151

20. Burri PH, Dbaly J, Weibel ER 1974 The postnatal growth of the rat lung. I. Morphometry. Anat Rec 178:711-730

21. Scherle WF 1970 A simple method for volumetry of organs in quantitative stereology. Mikroskopie 26:57-60

22. Cruz-Orive LM, Weibel ER 1981 Sampling designs for stereology. J Microsc 122:235-257

23. Zeltner TB, Bertacchini M, Messerli A, Burri PH 1990 Morphometric estimation of regional differences in the rat lung. Exp Lung Res 16:145-158

24. Mueller AE, Cruz-Orive LM, Gehr P, Weibel ER 1981 Comparison of two subsampling methods for electron microscopic morphometry. J Microsc 123:35-49
25. Humbert D, Cruz-Orive LM, Weibel ER, Gehr P, Burri PH, Hoppeler H 1990 STEPone - an interactive program for manual stereology. Acta Stereol 9:111-124

26. Weibel ER 1979 Volume I. Stereological Methods. Practical Methods for Biological Morphometry. Academic Press, London

27. Weibel ER, Federspiel WJ, Fryder-Doffey F, Hsia CCW, König M, Stalder-Navarro V, Vock R 1993 Morphometric model for pulmonary diffusion capacity. Respir Physiol 93:125-149

28. Caduff JH, Fischer LC, Burri PH 1986 Scanning electron microscopic study of the developing microvasculature in the postnatal rat lung. Anat Rec 216:154-164

29. Bruce MC, Honaker CE, Cross RJ 1999 Lung fibroblasts undergo apoptosis following alveolarization. Am J Respir Cell Mol Biol 20:228-236

30. Schittny JC, Djonov V, Fine A, Burri PH 1998 Programmed cell death contributes to postnatal lung development. Am J Respir Cell Mol Biol 18:786-793

31. Burri PH 1998 Development and growth of the lung. In: Fishman AP, Elias JA, Fishman JA, Grippi MA, Kaiser LR, Senior RM (eds) Pulmonary Diseases and Disorders. McGraw-Hill, New-York, pp 91-105

32. Mercurio AR, Rhodin JAG 1978 An electron microscopic study on the type I pneumocyte in the cat: pre-natal morphogenesis. J Morphol 156:141-156

33. Morishige WK, Joun NS 1982 Influence of glucocorticoids on postnatal lung development in the rat: possible modulation by thyroid hormone. Endocrinology 111:1587-1594

34. Schwyter M, Burri PH, Tschanz SA 2003 Effects of glucocrticoids on geometrical properties of lung parenchyma in rats. Biol Neonate (in press)

35. Burri PH, Sehovic S 1979 The adaptive response of the rat lung after bilobectomy. Am Rev Respir Dis 119:769-777

36. Massaro D, Teich N, Maxwell S, Massaro GD, Whitney P 1985 Postnatal development of alveoli: regulation and evidence for a critical period in rats. J Clin Invest 76:1297-1305 